\title{
Eleições 2016: Pinhais
}

Gloria Estevinho ${ }^{1}$

- Enviado em 15/09/2016

- Aprovado em 18/09/2016
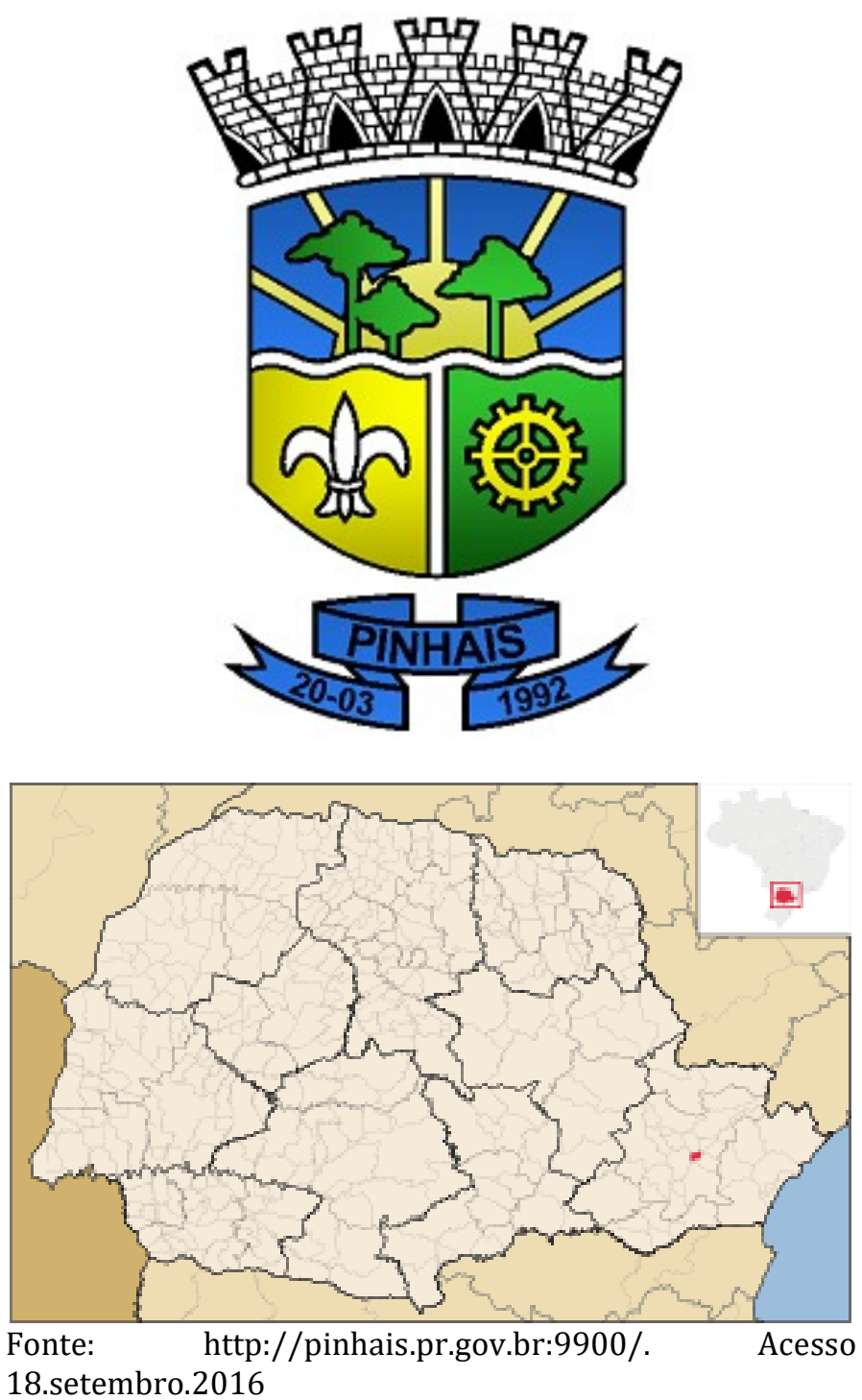

${ }^{1}$ Graduada em Ciências Sociais pela UFPR. Endereço eletrônico: stevinho_gomes@hotmail.com 


\section{Eleições 2016: Pinhais}

Gloria Estevinho

Para 2016, o Município de Pinhais, conta com candidatos que possuem uma trajetória política na região. Como candidatos válidos para concorrer ao pleito, no cargo de prefeito(a) e vice- prefeito(a) três nomes significativos, são lançados na disputa. Entre os(as) candidatos(as) da situação, está a atual vice-prefeita Marli Paulino, que concorre com o número 12, pelo PDT. Ela foi, por dois mandatos vice do Prefeito Luiz Goulart (PT), eleito com $93,77 \%^{2}$ dos votos válidos em 2012. Compõem sua chapa como vice, Rosa Maria (PROS), na coligação "Pinhais Segue em Frente" com participação de 15 partidos ${ }^{3}$. A trajetória das candidatas é conhecida no município e, sendo da situação, contam com a memória recente das ações realizadas pela prefeitura. Vale observar a participação da mulher na política, nesse caso. A oposição é feita pela coligação "Pinhais não pode Parar" do, também conhecido da região, Airton Pereira - Passarinho do (PSDC) que tem como vice Márcia Ferreira do PMDB, concorrendo com o número 27, e conta com a participação de 8 partidos $^{4}$. 0 terceiro candidato a prefeito pela oposição, é do PTB, José Claudio Stevani, o Claudinho Stevani, é o número 14, seu vice é Dener Cleyton Chaerki, o Cleyton da Farmácia (PTdoB), na coligação "Pinhais Merece mais" que conta com 2 partidos 5 . 0 município tem 200 mil eleitores, e o candidato que obter a maioria simples levará a vitória nas urnas e governará Pinhais pelos próximos 4 anos, gestão 2017 a 2020. Em função da revisão biométrica o número de eleitores sofreu uma considerável redução de 89.285, em 2012, para 76.626 o equivalente a 12.659 eleitores a menos (uma redução de $14,68 \%)^{6}$

\footnotetext{
2 Esse índice equivale, no período, a 62.802 votos. Seus opositores Flávio Borres do PSDB com 5.37\% corresponde a 3.596 votos e o terceiro candidato José Martins (PRP) computa 0,86\%, o equivalente a579 votos. Uma disputa, na prática, quase sem oposição.

3 PDT / PT / PMN / PPS / PROS / PC do B / PSL / PR / PSC / DEM / PRTB / PTC / PV / PRP / PMB / PSB

4 PSDC / PMDB / PTN / PRB / PSDB / PHS / PPL / PSD

5 PTB / PT do B

${ }^{6} \underline{\mathrm{http}}: / /$ www.chicaosomavilla.com.br/os-numeros-da-eleicao-municipal-de-pinhais-por-fabio-cristiano/
} 
Em 2014, Marli Paulino, se licencia da vice prefeitura para concorrer ao cargo de Deputada Estadual atingindo 34.293 (0.59\%), ficando como suplente. Assim, retornando ao antigo cargo na prefeitura. Com isso, ganha representatividade para atual disputa no executivo municipal. Sua vice, Professora Rosa Maria(PT), concorre a Deputada Federal e faz 29.725 (0.52\%), do mesmo modo, como suplente assume a Secretaria de Administração do município.

O candidato da coligação "Pinhais não pode parar", traz dois nomes conhecidos. Ele empresário, empreendedor e pioneiro no ramo de automóveis, um dos fundadores da ASSOVEPAR, vereador da Câmara Municipal e, sua vice, Marcia Ferreira que é socióloga, liderança do movimento estudantil e comunitário, sempre atuante a favor do empoderamento das mulheres do município, vereadora conhecida, pelo volume de projetos apresentados nesta legislatura, e referência de gestão da Secretaria Municipal de Assistêncial.

Os outros candidatos são José Claudio Stevani, que foi candidato em 2014 a Deputado Federal pelo PV, empresário ${ }^{7}$ do ramo do transporte de carga rodoviária, não se elegeu. Atualmente concorre, pela coligação "Pinhais merece mais" é do PTB e tem como vice Dener Cleyton Chaerki, ou simplesmente, Clayton da Farmácia - do mesmo partido. Seu vice, é também, proprietário de uma farmácia na Avenida Iraí, com o nome original de Iraí farmácia.

Vemos que os candidatos, em função do tamanho do colégio eleitoral do Município, são de origem migratória oriundos, basicamente do interior do Paraná, e em diferentes épocas. Ao estabelecerem-se na região, posteriormente inscrevem-se na política. 0 desafio aos opositores que não possuem trajetória política, é o de ganhar a confiança dos eleitores que se encontram divididos entre os demais que contam com o apoio, em algum grau, da atual administração. Isso porque dos 6 nomes 4 vem de uma cadeira no legislativo ou no executivo. Então, em termos eleitorais, temos mais do mesmo.

http://g1.globo.com/pr/parana/apuracao/pinhais.html

7 Com um patrimônio declarado no TSE de R\$ 2.586.675,99 Fonte: TSE 31/07/2014. Disponível em: http://www.gazetadopovo.com.br/vida-publica/eleicoes/2014/candibook//candidato/jose-claudio-stevanijose-claudio-stevani-pv-4334/. Acesso em 17/09/2016 
ANEX0:

\section{Candidatos a prefeito em PINHAIS PR}

Dados do TSE em 20-08-2016 06:28

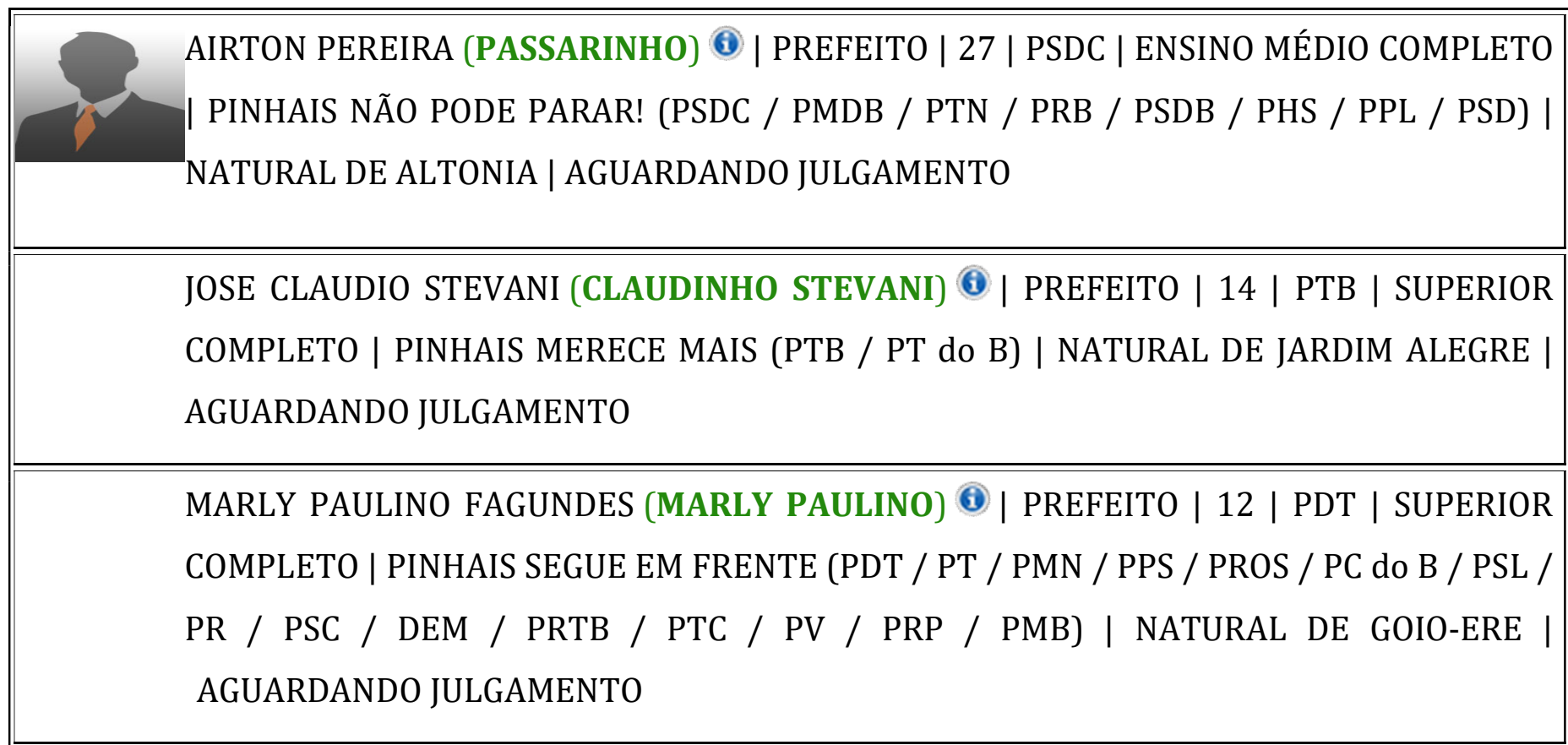

\section{Candidatos a vice-prefeito em PINHAIS PR}

\section{Dados do TSE em 20-08-2016 06:28}

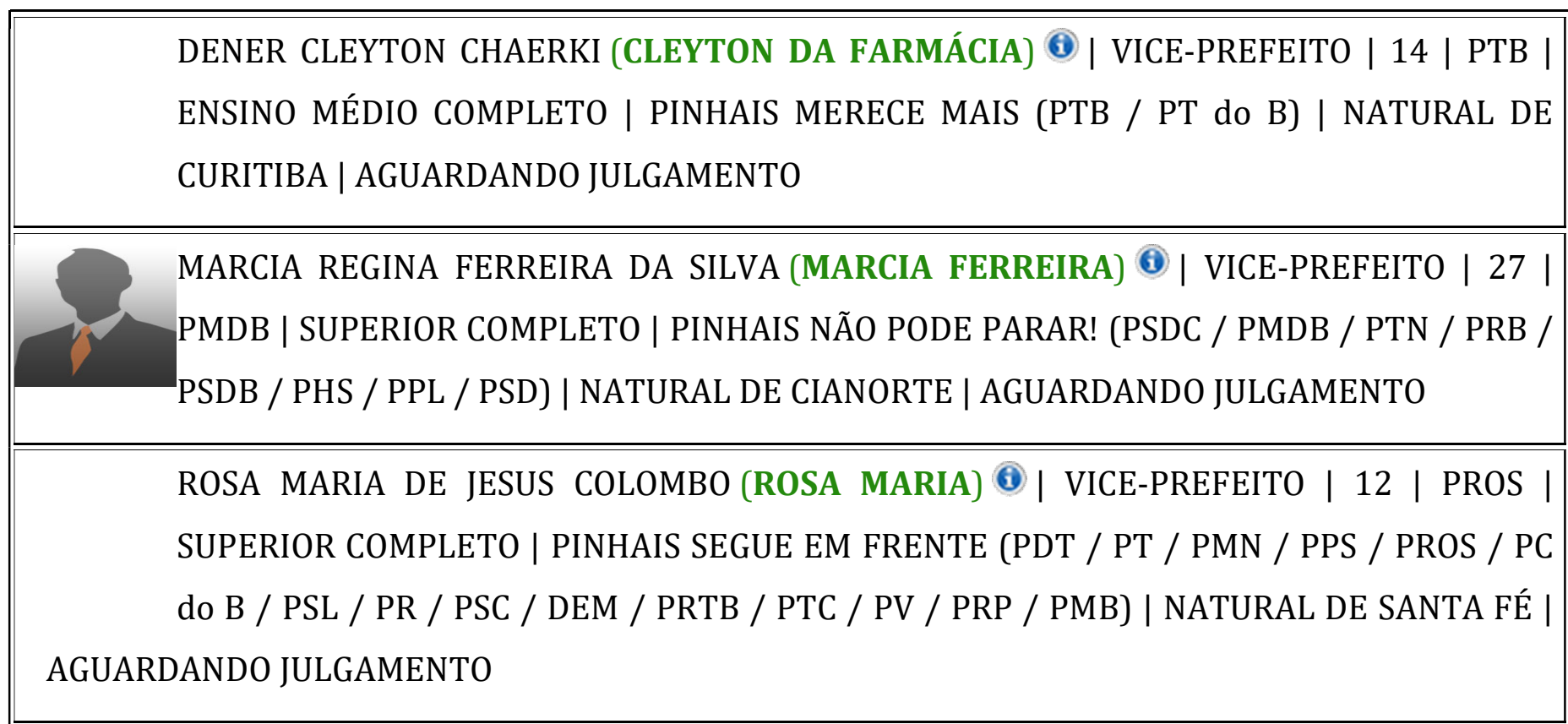

